\title{
Lessons from the fastest Brazilian unicorn
}

Lessons from the fastest Brazilian unicorn

\author{
André Luiz Tavares Damasceno, Cristiano Morini and \\ Gean Lucas Pannellini \\ Applied Science Faculty (FCA), University of Campinas (Unicamp), Limeira, Brazil
}

\begin{abstract}
Purpose - The purpose of this paper is to analyze the process of why a Brazilian digital startup company reached unicorn status the fastest.

Design/methodology/approach - After the literature review, the authors conducted the questionnaire containing 13 questions used in 18 in-depth interviews conducted in the case study. Saturation point combined with the independent and in-depth analysis of the researchers is used to achieve internal and external validity. The primary data collected underwent an analytical approach, followed by a resource-based view (RBV). RBV does not deal with time. There is a gap in the literature and an opportunity here: to analyze the fastest company to become a unicorn under the RBV lens.

Findings - The case reveals that value can be found in traditional sectors, as is the case of the real estate sector. This is a case of a company in the direct home-buying space.

Practical implications - The contribution of this paper is both practical, with the seven lessons, and theoretical. Resources allocated to a specific context in a specific geographic region shift the attention away from the absolute value of resources to the timing of aggregating them. Thus, the contribution accounting for time is new to the RBV.

Originality/value - The originality lies in the analysis of the dynamics of digital businesses with exponential growth.
\end{abstract}

Keywords Digital entrepreneurship, Innovation, Case study, Startup, Unicorns, RBV

Paper type Case study

\section{Introduction}

Digitalization, with the accelerated adoption of technologies in all areas of human life - work, study, entertainment and relationships - is a path of no return and the most important force of entrepreneurship and innovation (Berger, von Briel, Davidsson, \& Kuckertz, 2019). Individuals, companies and governments strive to get a hold of the fast-changing environment and somehow understand its compatibility with their principles, values and practices (Arlott, Henike, \& Hölzle, 2019). However, studies about the dynamics of digital entrepreneurship in emerging economies are still scarce (Al-Khateeb, 2019).

Contemporary entrepreneurship is driven by digital entrepreneurship, especially in innovation-driven countries (GEM, 2020). The digital ecosystem includes big techs (such as Apple, Microsoft, Amazon and Alphabet, among others) and startups of different sizes and sectors of activity, considering that digital entrepreneurship is defined as the process of the entrepreneurial venture to create value in digital streams (Sahut, Iandoli, \& Teulon, 2019).

Businesses that reach the unicorn status have been growing significantly, but discussions remain rare in the literature, representing an opportunity: to explore unicorn companies and

(C) André Luiz Tavares Damasceno, Cristiano Morini and Gean Lucas Pannellini. Published in Innovation \& Management Review. Published by Emerald Publishing Limited. This article is published under the Creative Commons Attribution (CC BY 4.0) licence. Anyone may reproduce, distribute, translate and create derivative works of this article (for both commercial and non-commercial purposes), subject to full attribution to the original publication and authors. The full terms of this licence maybe seen at http:// creativecommons.org/licences/by/4.0/legalcode.

The authors thank the anonymous reviewers for their valuable comments on the manuscript. The authors also thank the participants in the interview process from Company A.
Received 5 May 2021

Revised 17 July 2021

28 September 2021

Accepted 3 November 2021 
unveil their inner characteristics. There are over 800 unicorn companies worldwide. Such companies are predominantly located in the US (370 companies or $51.2 \%$ ) and China (210 or $29 \%$ ). Brazil is the 8th country in the total number of unicorns, with 12 (CB Insights, 2019). To encourage research on such companies, this paper seeks to analyze the characteristics of the startup that reached unicorn status the fastest in Brazil (and one of the fastest in the world), within only 16 months of operation.

Given this context, this study seeks to answer the following research question: What makes a startup achieve unicorn status in the fastest way? According to Zahra (2021), future resource-based view (Barney, 1991) research must consider time. Zahra (2021) states that startup companies offer an environment where resource combinations are likely to emerge, emphasizing that time is required to learn and decipher how to convert resources into commercial applications. However, current RBV studies do not deal with time, thus representing a gap in the literature as well as an opportunity: to analyze the fastest company to become a unicorn under RBV lens.

The contribution of this study lies in its analysis of how fast a company became a unicorn. We start from a literature review, presenting the concepts related to digital economy, digital ecosystems, and unicorn companies. Next, we explain the methodology and the questions that emerged from the literature review. Next, a case study protocol is presented with data collection and analysis. We then offer a discussion from the questions raised, structuring the results with theoretical implications. Finally, we conclude by presenting seven lessons learned as a practical contribution and presenting the theoretical contribution.

\section{Literature review}

\subsection{Digital economy and digital business}

The digital economy that was enabled and enhanced by technological discoveries since the 1960s has been transforming the business world. After continuous improvements in hardware and software, we must mention the maturation and popularization of the technology used by people from all social classes (Met, Uysal, Özkaya, \& Orç, 2020). This led to organizations applying digital business paradigms (Drew, 2003; Ghosh, 2002).

The migration process to the economic order dictated by digital business models has already shown trends that became organizations' paradigms: declining transaction costs, broader supply of information via the internet, and instability of business models (Whitley \& Darking, 2006). Customer service and the creation of superior and exclusive value propositions should be at the heart of strategy and innovation initiatives (Bei, Jin, \& Ieee, 2005). Despite the antiquity of the studies, these premises remain true. Technology offers great opportunities and also great threats (Met et al., 2020).

One of the essential characteristics of digital business models is their constant evolution (Baber, Ojala, \& Martinez, 2019), both in modern service-based economies (Bygstad, Aanby, \& Iden, 2017; Hirte \& Roth, 2018; Peter, Kraft, \& Lindeque, 2020; Pin, 2014) and in emerging economies (Boojihawon \& Ngoasong, 2018; Grabra \& Manole, 2017; Mahmud, 2020; McAdam, Crowley, \& Harrison, 2018). In this new paradigm, "digitality" plays a central role as a means of generating value for the client (Rantala, Ukko, Saunila, Puolakoski, \& Rantanen, 2019), especially when leaders are aware of, and committed to, the process of digital transformation (Bygstad et al., 2017; Locoro \& Ravarini, 2019).

Modularity, open innovation and platforms are characteristic elements of digital business models (Sturgeon, 2019). Wiesböck and Hess (2020) stress that, in addition to using technology to provide new solutions for customers, it is necessary to consider the mechanisms that support the facilitation of digital innovation and the governance of processes and activities. The latter, far from limiting the generation of solutions, organizes and directs solutions for the company to prioritize the launch of innovations that meet 
customers' needs, minimize the risks of failure, and increase the chances of sustained future growth (Ries, 2011). Sustainable growth also depends on the company's ability to collect, analyze and use the information obtained, leveraging improvements in the value chain and developing new business ideas (Tohanean \& Weiss, 2019).

Peter et al. (2020) contribute significantly to the understanding of digital transformation drivers, namely (1) process engineering; (2) new technologies and digital business development, supported by digital leadership and culture; (3) cloud and data; (4) customer focus; and (5) digital marketing. The success of digital business models depends, among other factors, on the skills acquired and developed by the organization's leaders (Ravarini, Locoro, \& Martinez, 2020; Sousa \& Rocha, 2019). Ratzinger, Amess, Greenman, and Mosey (2018) assessed the impact of formal partner education on the ability to attract investments. Their research highlights that companies with partners with a higher degree in management and technical education are more likely to attract foreign investment. The startups, choosing the path of experimentation, learning, and rapid adaptations of products and services, aim to convince, at the same time, (1) potential customers often suspicious of the world of digital consumption (Konya-Baumbach, Schuhmacher, Kuester, \& Kuharev, 2019) and (2) investors, eager for businesses that offer value and growth drivers (Cavallo, Ghezzi, Dell'Era, \& Pellizzoni, 2019; König, Ungerer, Baltes, \& Terzidis, 2019; Panda, 2019).

\subsection{Digital ecosystems and digital entrepreneurship}

Although lacking a more objective conceptualization (Sussan \& Acs, 2017), digital ecosystems present observable characteristics, among which (1) stimulus to collaboration between the university, public agencies, and companies; (2) management practices that allow rapid experimentation of new products and services; and, as White (2012) points out, (3) the adoption of digital workplaces, seeking to stimulate team's productivity.

The digital entrepreneur differentiates himself by seeking solutions and business models feasibility based on the internet and current technologies (Ngoasong, 2018). In addition, emerging economies play a relevant role in offering solutions to fill institutional voids that lead to inequality and the weakening of the social fabric (Martinez Dy, 2019; McAdam, Crowley, \& Harrison, 2019).

At the heart of entrepreneurial and digital ecosystems are agile practices, which help to revolutionize creating and managing a business. This movement, which has roots in the Japanese movement of Total Quality and in software development practices popularized in the 1990s and 2000s, is called Lean Startup Approach, LSA (Carroll \& Casselman, 2019; Ghezzi, 2019; Ghezzi \& Cavallo, 2020; Sanasi, Ghezzi, Cavallo, \& Rangone, 2019). These practices have been influencing a new generation of digital entrepreneurs (Remane, Hanelt, Nickerson, \& Kolbe, 2017; Tangour, Gebauer, Fischer, \& Winkler, 2019), the creation of new products and services, and the improvement of the value chain and organizational processes.

The economic relevance of the digital industry giants that have been successful in creating ecosystems around them (Valdez-De-Leon, 2019), as in the successful experience of digital transaction platforms (marketplaces) (Hänninen, 2019), demonstrates the seriousness of the theme. However, even considering the value that many digital businesses generate for their customers, a broader approach should also consider how traditional businesses are affected by the new digitality paradigm (Rantala et al., 2019). The resistance of actors who feel harmed by the generated innovations can cause institutional turbulence, limiting the economic opportunities of digital entrepreneurship (Geissinger, Laurell, Sandström, Eriksson, \& Nykvist, 2019).

Furthermore, according to Rodrigues and de Noronha (2021), the digital business model adopted by startups can support traditional businesses facing systemic crises. Analyzing the context of the COVID-19 pandemic, the authors list three main actions, namely (1) the adoption of new digital platforms; (2) strategies to increase the network of partners; and
Lessons from the fastest Brazilian unicorn 
(3) adaptations in the provision of payment services. Access to financial resources for developing digital entrepreneurs is vital to leverage the digital innovation process, especially in emerging markets (Balodi, Jain, \& Das, 2021; Tanrıkulu \& Ermiş, 2021).

\subsection{Unicorns}

Unicorns are companies whose value exceeds US $\$ 1$ billion. The term "unicorn" was coined by Aileen Lee, founder of VC fund Cowboy Ventures in 2013 (Lee, 2013). In Lee's paper (2013), she states that the process of becoming a unicorn is not a sprint race but a marathon. Observing 39 companies in her studied published in 2013, she stated it takes seven years on average for the company's value to exceed US\$ 1 billion. Lee's paper (2013) also pointed out the founder's background is from well-known universities with technical degrees. Lee stated that unicorns tend to raise a lot of capital over time (beyond Series A). Additional series seed funding of a startup may go further to Series B, C, D, or E (series are new cycles of raising investments, depending on the potential of the business and the market's expansion possibility. The amount of capital-raising on each series is not defined previously).

Unicorns play an essential role as catalysts of innovation and often impact regional economies (Acs, Stam, Audretsch, \& O'Connor, 2017). Jinzhi and Carrick (2019) conducted a two-stage case study involving 68 Chinese unicorns, followed by a deeper analysis of two of them. The authors identified three main catalysts: strategic alliances, strong government relations, and founders with appropriate experience and skills.

Chillakuri, Vanka, and Mogili (2020) point out the difficulty of Indian startups, usually lacking elements found in sustainable ecosystems, such as government support, elimination of red tape, access to investment, and mentoring programs. Cowden, Bendickson, Bungcayao, and Womack (2020) argue that unicorn leaders must operate in an environment that balances corporate governance mechanisms because unicorns are organizations that operate in environments of extreme uncertainty, where experimentation and learning are present more often than in traditional businesses (Ries, 2011).

Finally, studying the challenge of creating startups that become sustainable unicorns, AuYong-Oliveira, Costa, Gonçalves, and Branco (2018) proposed a theoretical framework. The relevance of their study lies in the identification of the fact that unicorns, when facing the pains of growth, must acquire and enhance four capabilities: (1) constant reformulation, (2) efficient anticipation, (3) profit generation, and (4) valuation control. Moreover, the digitalization of the value chain is also a challenge when the organization considers internationalization (Vadana, Torkkeli, Kuivalainen, \& Saarenketo, 2020).

In the next section, we define the path taken to analyze Company A (the case study of this paper).

\section{Methodology}

\subsection{Bibliographic portfolio}

The papers used in this research were extracted from the Scopus and Web of Science databases. The databases were consulted in two phases, aiming to extract papers containing (1) documents on the topic "digital business" and (2) on the topic "unicorns," as explained in detail next.

3.1.1 Phase I. Avoiding the potential loss of relevant papers, generic search terms were chosen (1) "digital business" and (2) "digital entrepreneurship", on both bases. The queries used at phase I are shown in Table 1. The complete process is presented in Figure 1. In the first rounds of extraction, we use the terms "startup" and "startup". However, the term "digital business" proved to be more appropriate, as it returned more complete results. Next, we use the term "unicorn", which allowed new papers to be added to the base. Thus, 307 documents were found, downloaded, and incorporated into the portfolio. 
3.1.2 Phase II. Papers on the topic "unicorns" were extracted according to the parameters presented in Table 2. The complete process is presented in Figure 2. Thus, 26 documents were found, downloaded, and incorporated into the total portfolio. Using the software VOS Viewer (Figure 3), a heat map was built containing the occurrences of the keywords of the papers (Phases I and II). The highest occurrence of words is concentrated in the middle. The small distance between the clusters formed demonstrates the homogeneity of the portfolio used in the research.

\subsection{Single case study}

Despite the lack of consensus on the appropriate criteria for evaluating qualitative studies, methodological consistency (Dixon-Woods, Shaw, Agarwal, \& Smith, 2004) and rigor in interpreting results (Lincoln, Lynham, \& Guba, 2011) are often considered to analyze the research design. In addition, problems regarding the validation of the qualitative study are

Baseline $\quad$ Parameter

Scopus

Web of science

TITLE-ABS-KEY ("digital business" OR "digital entrepreneurship”) * all years; * all themes

TOPIC: ("digital business" OR "digital entrepreneurship")

Refined by: WEB OF SCIENCE CATEGORIES: (MANAGEMENT OR BUSINESS)

Timespan: All years. Indexes: SCI-EXPANDED, SSCI, A\&HCI, CPCI-S, CPCI-SSH, ESCI
Lessons from the fastest Brazilian unicorn

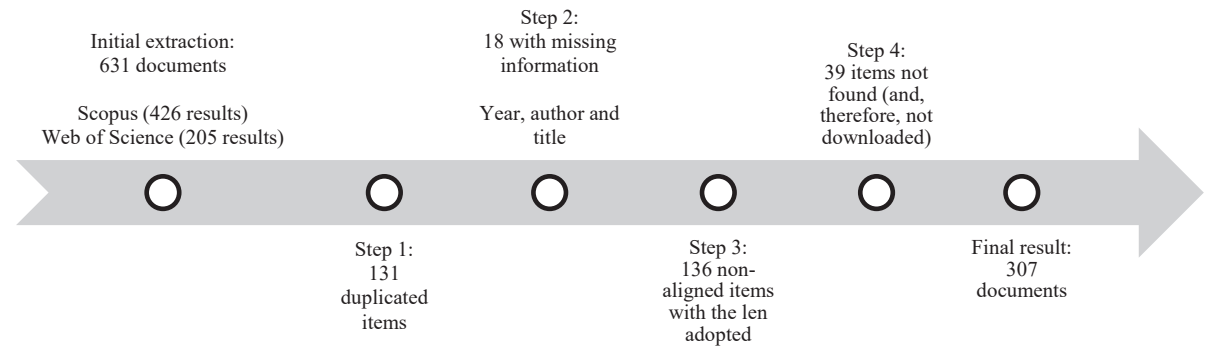

\begin{tabular}{ll}
\hline Baseline & Parameter \\
\hline Scopus & TITLE-ABS-KEY ("unicorn” AND “entrepreneurship") * all years; * all themes \\
Web of science & TOPIC: (entrepreneurship) AND TOPIC: (unicorn) \\
& Timespan: All years. Databases: WOS, DIIDW, KJD, RSCI, SCIELO \\
& Search language = Auto
\end{tabular}

Table 1. Queries used in Phase I
Figure 1.

Results of paper extraction (Phase 1)

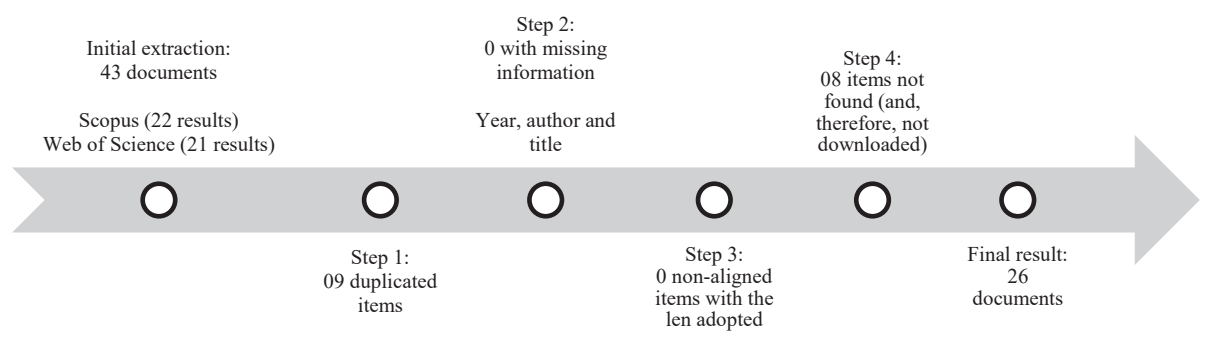

Figure 2.

Results of the paper extraction (Phase 2) 


\section{INMR}

Figure 3.

Analysis of the portfolio of papers (Phase I and Phase II) using the VOS viewer

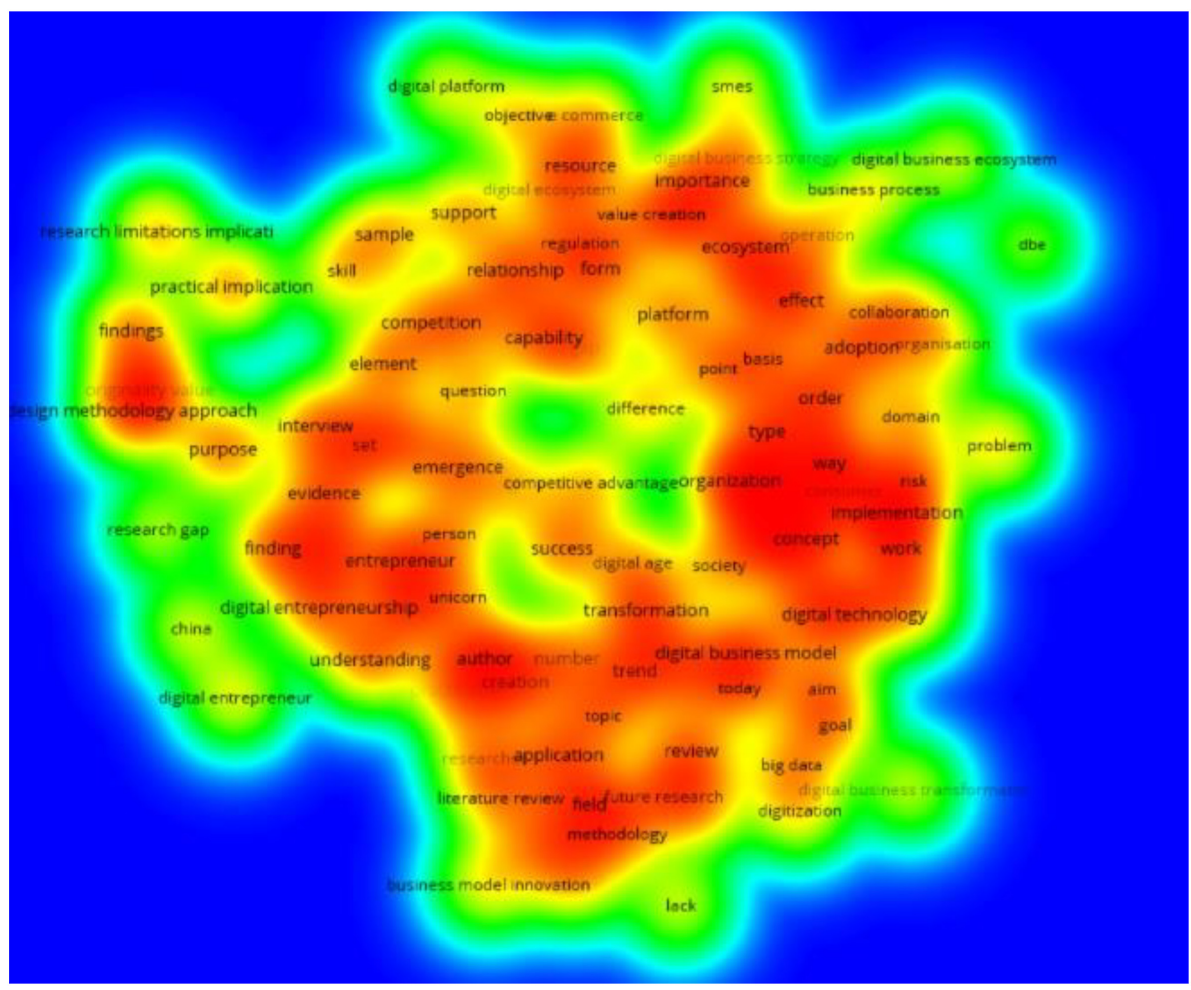

mitigated through appropriate techniques, such as the triangulation between research and theories (Leung, 2015; Mariotto, Zanni, \& Moraes, 2014).

The approach used to study this case is exploratory (Yin, 2003), identifying objective and subjective elements present in the narrative of interviewees. From this step, we then conducted the analytical approach from the primary data collected and then confronted the results with existing theories. Finally, following Eisenhardt (1989), we took enfolding literature comparison with conflicting literature. It is worth mentioning that case studies typically combine data collection methods such as interviews, questionnaires and observations.

Company A was founded in 2018 in Sao Paulo, the biggest Brazilian city (both in the gross domestic product (GDP) and population), and operates in the real estate sector (in what has also been called proptech). The company has been exploring opportunities in a traditional sector that usually offers little space and willingness for innovation. Even so, the company became a unicorn in Brazil faster than any other: in only 16 months.

The first Brazilian unicorn was created in 2012 in Sao Paulo and surpassed US $\$ 1$ billion in market value in 2018 (six years later). Company A's main digital competitor in Brazil was founded in 2013 and became a unicorn as late as 2019.

Company A's business model is called online direct home-buying. This business model is unique in Brazil and consists of purchasing a home from its owner, improving it with technology and other methods, and rapidly listing it on the market. The company gains from the appreciation and protects itself by charging a fee from the owner, which protects the company from depreciation. This model is attractive because it allows sellers to sell their 
homes immediately. For the buyer, the transaction costs are reduced due to the online direct home-buying model. However, the properties must comply with specific characteristics defined by geographical region, size and materials used in the construction.

RBV emphasizes the analysis from the perspective of resources and not from products and services generated (Wernerfelt, 1984). Thus, we consider it to be adequate for the context of this research. According to RBV, economic value is created by co-specialization by either increasing the willingness of customers to pay for products or services or reducing other costs (Barney, Ketchen, \& Wright, 2021).

In 2019 and 2020, acquisitions were made to improve new fronts (Table 3). After two years of operation, the growth made the company reach the number of 700 employees (of which 200 were hired during the pandemic of COVID-19). This hiring was also due to the expansion of operations to Rio de Janeiro, the second largest Brazilian city.

\subsection{Data collection}

The researchers conducted the interviews in the period between July and November 2020. The recordings of the interviews were transcribed into text. To contribute to replicability and to verify the internal validity of results from the interviews, the authors used Iramuteq $(0.7$ alpha 2), an open software used for statistical analysis of the texts.

The sample selection in qualitative research considers the sample representativeness (Table 2 shows the profile of the professionals interviewed). Methods such as triangulation with the researchers were employed to increase internal validity. The 20 -h recorded file of interviews can be tracked and audited.

We adopted the snowball sampling technique in which respondents are asked to encourage the participation of other people (belonging to the target audience) in the research (Alam, 2021; Cunningham \& Carmichael, 2017). To define the ideal sampling, the technique takes into account the authors' judgment in order to verify the saturation point of the data collection (Bhattacharyya, 2020; Izadfar, Sharififar, \& Mohammadkazemi, 2020; Martins \& Nunes, 2016). The authors asked respondents to nominate other professionals from key areas in the company to collaborate with the research. As a result, the saturation point of the 13 questions was reached after 18 interviews (Table 4).

At the end of each round, we checked the answers. When the repetition of responses in each question was detected more than three times, it was considered that the saturation point had been reached for the given question (Table 5). When this happened with all questions, the interviews were terminated. Saturation, combined with the independent and in-depth analysis of the three researchers (authors of this paper), contributes to improving the research's internal validity and the research protocol.

3.3.1 Questions. The papers used in the literature review allowed us the identification of key themes that should be addressed. The questions used in the interviews are supported by the systematic literature review conducted by this research (Table 6).

\subsection{Data analysis}

Discourse analysis seeks to understand the meaning of narratives, considering language not only as a communication system but also as a tool to express ideas, feelings, and views of

\begin{tabular}{lll}
\hline Company & Field of activity & Acquisition in \\
\hline B & Property reform & November/2019 \\
C & Data analysis & February/2020 \\
D & Coliving & April/2020 \\
E & Rentals and short stays & July/2020 \\
F & Credit & September/2020
\end{tabular}

Lessons from the fastest Brazilian unicorn

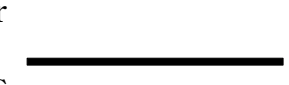


INMR

\begin{tabular}{lll}
\hline Identification & Organizational role & Position \\
\hline Interviewee_01 & Commercial & Technician \\
Interviewee_02 & Analytics & Technician \\
Interviewee_03 & Channels & Management \\
Interviewee_04 & Channels & Technician \\
Interviewee_05 & Technology & Technician \\
Interviewee_06 & Product & Technician \\
Interviewee_07 & Marketing & Technician \\
Interviewee_08 & Marketing & Technician \\
Interviewee_09 & Finance & Technician \\
Interviewee_10 & Finance & Technician \\
Interviewee_11 & Analytics & Management \\
Interviewee_12 & Legal & Management \\
Interviewee_13 & Human resources & Technician \\
Interviewee_14 & Human resources & Technician \\
Interviewee_15 & Human resources & Technician \\
Interviewee_16 & Technology & Technician \\
Interviewee_17 & Technology & Technician \\
Interviewee_18 & Legal & Management \\
\hline
\end{tabular}

Table 4.

Interviewee's data

\begin{tabular}{ll}
\hline Questions & Saturation point reached in the following interview \\
\hline Q_01 & 8th \\
Q_02 & 11th \\
Q_03 & 18 th \\
Q_04 & 14 th \\
Q_05 & 6 th \\
Q_06 & 18th \\
Q_07 & 12th \\
Q_08 & 18th \\
Q_09 & 18th \\
Q_10 & 18th \\
Q_11 & 12th \\
Q12 & 12 th \\
Q13 & 14th
\end{tabular}

individuals about the reality contemplated (Brown, Brown, Brown, Gillian, \& Yule, 1983; Eisenhardt, 1989; Johnstone, 2017). The technique was used in the effort to analyze the audiorecorded interviews, guiding the authors in understanding the interviewees' speeches from their social context, which may impact their perception of reality. For example, a company's collaborative and social aspects and the actors that compose it (including managers and employees) often generate subjective and contradictory perceptions regarding the relevant issues and themes of professional daily life.

The authors analyzed the transcript of the 18 interviews, identifying the critical elements exposed by the professionals interviewed. The authors were guided by the main objective of the paper, each of the questions used in the interviews, and the knowledge of the organization that was progressively acquired. This allowed them to fill gaps and align conflicting views observed during the interviews. When necessary, the interviewees were consulted afterward to clarify points that were not entirely understood in the analysis of the transcriptions. 


\begin{tabular}{ll}
\hline ID & Question \\
\hline Q01 & $\begin{array}{l}\text { What elements were predominant for the choice of the } \\
\text { real estate sector by the partners? }\end{array}$ \\
Q02 & $\begin{array}{l}\text { How does the company track and incorporate changes } \\
\text { in its customers and users profile? }\end{array}$ \\
Q03 & $\begin{array}{l}\text { What strategies does the company use to deal with } \\
\text { copycats of its products and services? }\end{array}$ \\
Q04 & $\begin{array}{l}\text { What are the most relevant stakeholders? }\end{array}$
\end{tabular}

Q05 How does the presence/absence in a digital ecosystem enhance the competitiveness of the company?

Q06 Are the employees encouraged to act like entrepreneurs?

Q07 How are the new ideas and projects from employee evaluated? And how are successful solutions rewarded?

Q08 What leadership and management skills are most needed to maintain the company's growth?

Q09 What individual contribution skills are most demanded by the company?

Q10 How does the company deal with the pains of organizational growth?

Q11 What are the main strengths and weaknesses of the Brazilian business environment, as an emergent economy? How do they positively and negatively affect digital businesses?

Q12 How can digital companies contribute to overcoming the weaknesses observed?

Q13 How the theme of sustainability - environmental and social - is addressed in the organization's daily life?

\section{References}

Carroll and Casselman (2019); Konya-

Baumbach et al. (2019)

Konya-Baumbach et al. (2019); König et al. (2019); Panda (2019)

Aversa et al. (2019)

Thomas \& Autio (2020); Sussan and Acs (2017); White (2012); Hofmann and Giones (2019)

Ghosh (2002); Beliaeva et al. (2019)

Locoro and Ravarini (2019); Sousa and Rocha (2019)

Locoro and Ravarini (2019); Sousa and Rocha (2019)

Locoro and Ravarini (2019); Sousa and Rocha (2019)

Stoian and Tohanean (2019)

Vadana et al. (2020)

Valdez-De-Leon (2019); Pin (2014) (Both authors analyze emergent economies)

Valdez-De-Leon (2019); Pin (2014)

Rantala et al. (2019)

Table 6. Questions and sources

\section{Results and discussion}

In this section, we analyze the transcriptions of the 18 interviews and the corresponding literature. The organization follows the same sequence used in the interview questions. The company adds value in a traditional sector and explores the RBV through its VRIO analysis, as valuable $(\mathrm{V})$, rare $(\mathrm{R})$, inimitable $(\mathrm{I})$, and organizationally $(\mathrm{O})$ embedded at the beginning (Barney, 1991, 1996). All session is analyzed through VRIO framework.

Addressing the potential of innovative new businesses, Ries (2011) argues that a successful business should offer exponential value and growth over time. Housing is a topic of great social relevance due to chronic deficiencies often observed in emerging countries (Martinez Dy, 2019; McAdam et al., 2019), and "it is a sector historically marked by inefficiency, bureaucracy, and customer experience below expectations, and not keen to accelerating changes through technology" (Interviewee_01). Here, we apprehend lesson one: efficient investment attraction in a market with a backlog of demand.

The experience accumulated by one of the partners, a company focused on Sao Paulo prime neighborhoods, contributed significantly to the sector selection. "In this period, it worked primarily with an elderly population - supposedly averse to technology - which was a challenge" (Interviewee_08) and a rare occurrence $(R)$ that, incidentally, is highlighted by Konya-Baumbach et al. (2019), when they point out that operational excellence is the basis of user experience by gradually acquiring the confidence to using technology. 
"The company is concerned with strengthening its brand by means of establishing trustworthy relationships to increase growth" (Interviewee_09), primarily through electronic word-of-mouth (Mihardjo, Sasmoko, Alamsjah, \& Elidjen, 2019).

"The company conducts tests of products and services aimed at customers and brokers, collecting feedback and adopting solutions according to the response of these audiences" (Interviewee_01). "The acquired know-how materializes in the business rules" (Interviewee_16) and "applications developed to support internal teams" (Interviewee_18). The company growth is due to applying the Lean Startup Approach (LSA), as Ghezzi (2019) pointed out, although the author did not consider the real estate company in its original work. Here, we apprehend lesson two: rapid experimentation of new products and services.

Among the techniques used and commented on during the interviews is the persona. "It is helpful to understand the current and new niches of action" (Interviewee_07) for accelerating the experimentation of new solutions (White, 2012). This can often prevent one from considering the (digital) business model only from the technology aspect (Slywotzky \& Morrison, 2001), as if technical innovation was, by itself, a guarantee of customer satisfaction. This is valuable $(\mathrm{V})$ and organizationally $(\mathrm{O})$ embedded at the beginning.

In addition, the entry into the credit market, through the acquisition of a fintech company, and the exploitation of a residential real estate fund offer constituted differential ingredients for company A. "The company's business model has significant entry barriers, including the large volume of capital required to operate" (Interviewee_01). Another important aspect is the company's use of resources as data technology and digital innovation. Data science dealing requires a team of highly well-trained people (Interviewee_01; Interviewee_11). Besides, establishing trustworthy relationships with brokers is also regarded as an essential competitive advantage (Interviewee_01; Interviewee_04; Interviewee_08), which is in line with the findings of Konya-Baumbach et al. (2019). The authors argued that positive customer ratings might serve as a trustworthiness signal for digital innovations. This is inimitable (I) at the beginning. Substitutability (Barney, 1991) is not easy to have in this context due to the innovativeness of the solutions. Here is lesson three: use of data and digital innovation as tech resources.

The generated relationship networks are among the potential competitive advantages for digital companies born and raised with the support of university innovation agencies (Thomas \& Autio, 2020). "The company was not incubated in an innovation agency, but the fact that experienced partners founded it facilitated the business designing and establishment" (Interviewee_02). The development of these relationships considered, from the beginning, that real estate brokerage is often regarded as a low added value activity. "Indirectly, the company has been helping to rescue the dignity and confidence of the realtor profession" (Interviewee_04). The establishment of key partnerships is valuable (V), and it confirms the findings of Beliaeva, Ferasso, Kraus, and Damke (2019). Then comes lesson four: improvement in communication and relationship with brokers through digital platforms.

"The company was benefited from its partners' experience" (Interviewee_03). "This fact also contributed to the attraction of venture capital investments to bear the costs of real estate operation and acquisition" (Interviewee_01), as mentioned earlier. The fact that the fastestgrowing startup company in Brazilian history does not come from an incubator is a finding that collides with other authors (Carayannis \& Von Zedtwitz, 2005; Hatakeyama \& de Melo Pinto, 2020; Tschanz et al., 2020).

"Company A has become a hub of important actors in the real estate sector" (Interviewee_09), predicting that, in the future, the company itself could be the chain's strong link, stimulating the launch of new businesses (Hofmann \& Giones, 2019). It is valuable (V) and opportunity-driven. Here comes lesson five: design of a consistent innovation strategy and partnerships.

The company's fast growth follows Cavallo et al. (2019) findings that show the role played by venture capital funds in the scaleup phase. Our own work confirms this finding. The fast 
attraction of the investors is related to a business model that has thrived in California (Open Door Labs), then being replicated for the first time in an emerging economy and a traditional sector of a dynamic city. "These ingredients seem the proper combination for the fastgrowing startup" (Interviewee_02). Inimitable (I) and organizationally (O) embedded at the beginning. Then, lesson six is connection with startups (matchmaking) to solve company demands.

In Series A, the company was able to raise about 20 million dollars. In Series B, it raised approximately 70 million, and in Series C, 175 million. In addition, the company participates in some real estate funds in Brazil, in which over 100 million dollars are available to execute their operation. With all these investments, in January 2020, the company reached the market value of 1 billion dollars and became the fastest unicorn in Brazilian history (Interviewee_02). Contrary to Chillakuri et al. (2020), who stressed the difficulty of a startup to attract investors in emerging economies, company A was able to attract investors until Series D.

In addition, the attitude of business owners is part of a startup's very essence (Ries, 2011). This is corroborated by the professionals (Interviewee_16; Interviewee_17) and is regarded as extremely valuable (Interviewee_02; Interviewee_03; Interviewee_05; Interviewee_06; Interviewee_13).

"Although there is no formal program for the submission of ideas, employees have, within the limits considered in the OKRs (Objectives and Key Results), autonomy to test proposals that contribute to activity improvement" (Interviewee_14). In cases where greater responsibility is involved, leaders, CDO (Chief Digital Officer), and CIO (Chief Information Officer) evaluate proposals from the employees, which confirms the high quality of human resources. Thus, it is possible to see that analytical skills are essential but not sufficient for forming high-performance teams (Stoian \& Tohanean, 2019). Without the commitment of the leaders (Bygstad et al., 2017; Locoro \& Ravarini, 2019), the competences lose their vigor. This resource is also valuable $(\mathrm{V})$.

Interviewee 2 stresses out that one founder is graduated from Harvard and the other from Wharton. The founders' skills are in tune with the findings of Sousa and Rocha (2019) and Ratzinger et al. (2018). Founders' higher education plays a significant role in the probability of receiving funding (Ratzinger et al., 2018). This is also in tune with Lee's assumption (Lee, 2013) that the founders of unicorns come from well-known universities and hold technical degrees, and with Jinzhi and Carrick (2019), who emphasize the appropriate skills and experience of the founders. According to (Barney et al., 2021), managers and entrepreneurs can be essential to value creation in aggregating resources and capabilities. It is valuable (V) and signals lesson seven: capable employees $(C D O, C I O)$ and teams as human resources.

Regarding the sustainability practices, the company helps, through a partnership with a social program, the renovation of properties for people living in poor communities in Sao Paulo (Interviewee_03). Internally, the company has been discussing topics such as racial and gender diversity (Interviewee_02; Interviewee_03; Interviewee_04; Interviewee_10). “The recruitment process does not consider the school attended by a candidate nor his English fluency, but his achievements and results and his projected potential” (Interviewee_15). Thus, digital businesses can accelerate the adoption of sustainable practices using technology (Chen, 2019) and promote financial performance by improving management skills (Ukko, Nasiri, Saunila, \& Rantala, 2019).

Conversely, various interviewees mentioned some of the chronic deficiencies of the Brazilian environment (and other emerging economies), such as (1) excessive taxes, (2) bureaucracy, (3) very plastered labor laws and (4) lack of transparency. In their view, some of the company's internal practices can mitigate the impact of such deficiencies, valuing results more than compliance with schedules (Interviewee_10; Interviewee_04), and "the search for solutions and establishment of transparent relationships with clients, transcending bureaucracy" (Interviewee_04).
Lessons from the fastest Brazilian unicorn

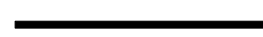


"The historical falling of the interest rate in Brazil can bring many financing opportunities" (Interviewee_02). A major limitation for the area is that there is no standard interest table for the real estate sector; therefore, "pricing remains a significant challenge" (Interviewee_08). Overcoming this and other chronic problems generated by institutional voids (McAdam, 2020; McAdam et al., 2019) can be achieved with cooperation between players in the sector. It is valuable (V). According to Barney (1991), when the competitive advantages are based on complex social phenomena, the probability of other firms' imitating is significantly lower.

\section{Final remarks}

From our study, we apprehended seven lessons, namely (1) efficient investment capture in a market with a backlog of demand, confirming the findings of Cavallo et al. (2019); (2) rapid experimentation of new products and services and assimilation of lessons learned, as pointed out by Ries (2011) and Ghezzi (2019); (3) use of data and digital innovation as technological resources, according to Konya-Baumbach et al. (2019); (4) improvement in communication and relationship with brokers through digital platforms, what is in tune to the finding of Le Dinh, Vu, and Ayayi (2018); (5) design of a consistent innovation strategy and partnerships, according to Beliaeva et al. (2019) and Barney (1996); (6) connection with startups (matchmaking) to solve company demands; and finally (7) capable employees (CDO, CIO) and teams as human resources, as we find in Locoro and Ravarini (2019), and Rodrigues and de Noronha (2021). These lessons are according to the VRIO framework; nonetheless, we emphasize that the lessons identified by this research are not exhaustive.

Resources are significant justification for the fast-growing performance of unicorns. According to RBV, investors will be where they can appropriate the most economic value, and a firm's resources and capabilities used to create such economic value must be rare (Barney et al., 2021). Company A did present a rare and inimitable (at least temporarily) online direct homebuying model, associated with the massive use of apps and 4G internet since 2013 in Sao Paulo.

According to Zahra (2021), financial resources are not enough since synchronization between intangible resources - such as the quality of the firm's human capital - and the quality and experience of its founders/managers, is required. This observation fits well Company A. The positive reputation of the founders, associated with their relationships and networking, was also a fundamental process of attracting investments and a potential source of competitive advantage (Barney, 1991).

Uniting value and growth prospects in the long term, the company facilitated investors' attraction and supported partners, managers, and teams in the ever-deeper knowledge of the needs and desires of owners, buyers and brokers. Value and growth are two aspects that should be present in a digital business with high potential for future results (Ries, 2011).

The case studied reveals that value can be found in traditional sectors with pent-up demand, as real estate. Even though in Ghezzi (2019) work, none of the companies was from the real estate sector, our work extends and corroborates his findings and confronts Lee's (2013) assumption, since Company A did become a unicorn in a sprint run, not in a marathon.

The company realized the possibility of using research in data science technologies (artificial intelligence, machine learning, big data, cloud computing) as resources to simplify the purchase and sale of real estate, thus developing solutions and improving the relationship with brokers, realtors, sellers, and buyers. Barney et al. (2021) state that research capabilities can sometimes generate innovative technological ideas, and according to Zahra (2021), the value of resources such as knowledge is defined by a combination with other resources and not only by the relation supply-demand.

Macroeconomic factors have also played a significant role in Company A's market. After a severe political and economic crisis during the period of 2014-2017 in Brazil, there has been a slow economic recovery. The basic interest rate of the Brazilian economy (SELIC) has reached 
the lowest levels in its history: from August/2016 to August/2020, SELIC fell from 14.25 to $2 \%$ (BACEN, 2020). With the more generous supply of credit, competition among the major banks for credit demanders and low real estate prices have created the ideal conditions for generating opportunities in the real estate sector.

The answer for the research question "What makes a startup achieve unicorn status in the fastest way?" regards that is the efficient anticipation (Au-Yong-Oliveira et al., 2018) in a market with chronic deficiencies as often observed in emerging countries is vital to understand one of the fastest companies to reach unicorn status in the whole world. In addition, the exploration of valuable opportunities in a traditional sector that usually observed little space and willingness for innovation (Martinez Dy, 2019; McAdam et al., 2019) is also necessary. Resources allocated to a specific context in a specific geographic region shift the attention away from their absolute value to the timing of aggregating them. This time issue is new to the RBV (it is noteworthy that time was understood in this study as the speed to become a unicorn).

Despite the research method chosen to avoid misinterpretation of the questions and bias, this paper shows as a limitation the data collected from a single case study in a specific sector. Therefore, future studies should analyze the relationship between the founders and the institutional approach, such as the role played by incubators, accelerators, and other aspects present in the innovation ecosystems, considering different unicorn categories.

\section{References}

Acs, Z. J., Stam, E., Audretsch, D. B., \& O'Connor, A. (2017). The lineages of the entrepreneurial ecosystem approach. Small Business Economics, 49(1), 1-10. doi: 10.1007/s11187-017-9864-8.

Al-Khateeb, B. A. A. (2019). The Conceptual Framework for the Examination of a Successful Digital Entrepreneurship in 21st Century. Advances in E-Business Research Series (pp. 126-141). Hershey: IGI Global.

Alam, M. K. (2020). A systematic qualitative case study: Questions, data collection, NVivo analysis and saturation. Qualitative Research in Organizations and Management: An International Journal, 16(1), 1-31.

Arlott, A., Henike, T., \& Hölzle, K. (2019). Digital entrepreneurship and value beyond: Why to not purely play online. In FGF Studies in Small Business and Entrepreneurship (pp. 1-22). Springer.

Aversa, P., Hervas-Drane, A., \& Evenou, M. (2019). Business model responses to digital piracy. California Management Review, 61(2), 30-58.

Au-Yong-Oliveira, M., Costa, J. P., Gonçalves, R., \& Branco, F. (2018). The rise of the unicorn: Shedding light on the creation of technological enterprises with exponential valuations. In 6th World Conference on Information Systems and Technologies, WorldCIST 2018 (Vol. 745, pp. 967-977), Springer Verlag.

Baber, W. W., Ojala, A., \& Martinez, R. (2019). Effectuation logic in digital business model transformation: Insights from Japanese high-tech innovators. Journal of Small Business and Enterprise Development, 26(6-7), 811-830. doi: 10.1108/JSBED-04-2019-0139.

BACEN (2020). Minutes of COPOM meetings (Transl. COPOM). Brasilia: Central bank of Brazil.

Balodi, K. C., Jain, R., \& Das, R. (2021). Strategy, business model, and innovation at Rivigo: Is relay-asa-service the way forward? Journal of Information Technology Teaching Cases, 1-10. doi: 10. 1177/2043886920986163.

Barney, J. B. (1991). Firm resources and sustained competitive advantage. Journal of Management, 17(1), 99-120.

Barney, J. B. (1996). The resource-based theory of the firm. Organization Science, 7(5), 469.

Barney, J. B., Ketchen, D. J., Jr, \& Wright, M. (2021). Resource-based theory and the value creation framework. Journal of Management, 1-20. doi: 10.1177/01492063211021655.

Bei, W., Jin, C., \& IEEE. (2005). E-innovation: A New Innovation Platform based on the Internet. New York: IEEE.
Lessons from the fastest Brazilian unicorn

ביר


Beliaeva, T., Ferasso, M., Kraus, S., \& Damke, E. J. (2019). Dynamics of digital entrepreneurship and the innovation ecosystem: A multilevel perspective. International Journal of Entrepreneurial Behaviour and Research, 26(2), 266-284. doi: 10.1108/IJEBR-06-2019-0397.

Berger, E. S. C., von Briel, F., Davidsson, P., \& Kuckertz, A. (2019). Digital or not - The future of entrepreneurship and innovation: Introduction to the special issue. Journal of Business Research, 125, 436-442. doi: 10.1016/j.jbusres.2019.12.020.

Bhattacharyya, S. S. (2020). Explicating firm international corporate social responsibility initiatives. Review of International Business and Strategy, 30(4), 515-536.

Boojihawon, D. K., \& Ngoasong, Z. M. (2018). Emerging digital business models in developing economies: The case of Cameroon. Strategic Change, 27(2), 129-137. doi: 10.1002/jsc.2188.

Brown, G., Brown, G. D., Brown, G. R., Gillian, B., \& Yule, G. (1983). Discourse Analysis. Cambridge: Cambridge University Press.

Bygstad, B., Aanby, H. P., \& Iden, J. (2017). Leading digital transformation: The Scandinavian way. In 8th Scandinavian Conference on Information Systems, SCIS 2017 (Vol. 294, pp. 1-14), Springer Verlag.

Carayannis, E. G., \& Von Zedtwitz, M. (2005). Architecting gloCal (global-local), real-virtual incubator networks (G-RVINs) as catalysts and accelerators of entrepreneurship in transitioning and developing economies: Lessons learned and best practices from current development and business incubation practices. Technovation, 25(2), 95-110.

Carroll, R., \& Casselman, R. M. (2019). The lean discovery process: The case of raiserve. Journal of Small Business and Enterprise Development, 26(6-7), 765-782. doi: 10.1108/JSBED-04-2019-0124.

Cavallo, A., Ghezzi, A., Dell'Era, C., \& Pellizzoni, E. (2019). Fostering digital entrepreneurship from startup to scaleup: The role of venture capital funds and angel groups. Technological Forecasting and Social Change, 145, 24-35. doi: 10.1016/j.techfore.2019.04.022.

CB Insights. (2019). CB insights' Global Unicorn Club Report. New York: CB Insights.

Chen, Y. S. (2019). Sustainable Development through Franchise Innovation in the Digital Economy Improving Business Performance through Innovation in the Digital Economy (pp. 39-57). Hershey: IGI Global.

Chillakuri, B., Vanka, S., \& Mogili, R. (2020). Linking sustainable development to startup ecosystem in India - A conceptual framework. International Journal of Business and Globalisation, 25(2), 139-153.

Cowden, B. J., Bendickson, J. S., Bungcayao, J., \& Womack, S. (2020). Unicorns and agency theory: Agreeable moral hazard?. Journal of Small Business Strategy, 30(2), 17-25.

Cunningham, N., \& Carmichael, T. (2017). Sampling, interviewing and coding: Lessons from a constructivist grounded theory study. In Paper Presented at the European Conference on Research Methodology for Business and Management Studies.

Dixon-Woods, M., Shaw, R. L., Agarwal, S., \& Smith, J. A. (2004). The problem of appraising qualitative research. BMJ Quality and Safety, 13(3), 223-225.

Drew, S. (2003). Strategic uses of e-commerce by SMEs in the east of England. European Management Journal, 21(1), 79-88. doi: 10.1016/S0263-2373(02)00148-2.

Eisenhardt, K. M. (1989). Building theories from case study research. The Academy of Management Review, 14, 532-550.

Geissinger, A., Laurell, C., Sandström, C., Eriksson, K., \& Nykvist, R. (2019). Digital entrepreneurship and field conditions for institutional change - Investigating the enabling role of cities. Technological Forecasting and Social Change, 146, 877-886. doi: 10.1016/j.techfore.2018.06.019.

GEM (2020). Global Entrepreneurship Monitor 2019/2020 Global Reports. London: Global Entrepreneurship Research Association and London Business School.

Ghezzi, A. (2019). Digital startups and the adoption and implementation of lean startup approaches: Effectuation, bricolage and opportunity creation in practice. Technological Forecasting and Social Change, 146, 945-960. doi: 10.1016/j.techfore.2018.09.017. 
Ghezzi, A., \& Cavallo, A. (2020). Agile business model innovation in digital entrepreneurship: Lean startup approaches. Journal of Business Research, 110, 519-537. doi: 10.1016/j.jbusres.2018.06.013.

Ghosh, P. (2002). The advent of information industrials. Journal of Business Strategy, 23(5), 43-47. doi: 10.1108/eb040274.

Grabra, I., \& Manole, A. L. (2017). Assessment of progressiveness of Polish and Romanian enterprises. Polish Journal of Management Studies, 16(1), 41-54. doi: 10.17512/pjms.2017.16.1.04.

Hänninen, M. (2019). Review of studies on digital transaction platforms in marketing journals. International Review of Retail, Distribution and Consumer Research, 164-192. doi: 10.1080/ 09593969.2019.1651380.

Hatakeyama, K., \& de Melo Pinto, N. (2020). The innovation system in the Brazilian scenario. In Paper Presented at the 29th International Conference of the International Association for Management of Technology: Towards the Digital World and Industry X.O, IAMOT 2020.

Hirte, R., \& Roth, P. (2018). Advanced innovation management: Best practice of German and American corporations in the mobility sector. In Paper Presented at the 2018 Portland International Conference on Management of Engineering and Technology, PICMET 2018.

Hofmann, M., \& Giones, F. (2019). Entrepreneurship as an innovation driver in an industrial ecosystem. In FGF Studies in Small Business and Entrepreneurship (pp. 99-121). Springer.

Izadfar, V., Sharififar, F., \& Mohammadkazemi, R. (2020). The business model of sports academies with an emphasis on value proposition and customer segments. Annals of Applied Sport Science, 8(4), $23-29$.

Jinzhi, Z., \& Carrick, J. (2019). The rise of the Chinese unicorn: An exploratory study of unicorn companies in China. Emerging Markets Finance and Trade, 55(15), 3371-3385. doi: 10.1080/ 1540496X.2019.1610877.

Johnstone, B. (2017). Discourse Analysis. New Jersey: John Wiley and Sons.

König, M., Ungerer, C., Baltes, G., \& Terzidis, O. (2019). Different patterns in the evolution of digital and non-digital ventures' business models. Technological Forecasting and Social Change, 146, 844-852. doi: 10.1016/j.techfore.2018.05.006.

Konya-Baumbach, E., Schuhmacher, M. C., Kuester, S., \& Kuharev, V. (2019). Making a first impression as a start-up: Strategies to overcome low initial trust perceptions in digital innovation adoption. International Journal of Research in Marketing, 36(3), 385-399. doi: 10. 1016/j.jijresmar.2019.01.008.

Le Dinh, T., Vu, M. C., \& Ayayi, A. (2018). Towards a living lab for promoting the digital entrepreneurship process. International Journal of Entrepreneurship, 22(1).

Lee, A. (2013). Welcome to the unicorn club: Learning from billion-dollar startups. Palo Alto: Cowboy Ventures (blog).

Leung, L. (2015). Validity, reliability, and generalizability in qualitative research. Journal of Family Medicine and Primary Care, 4(3), 324.

Lincoln, Y. S., Lynham, S. A., \& Guba, E. G. (2011). Paradigmatic controversies, contradictions, and emerging confluences, revisited. The Sage Handbook of Qualitative Research, 4, 97-128.

Locoro, A., \& Ravarini, A. (2019). The CIO and CDO socio-technical roles in the age of digital business transformation: An interpretive study. Lecture Notes in Information Systems and Organisation, 28, 235-245. doi: 10.1007/978-3-319-90503-7_18.

Mahmud, M. (2020). Impact analysis of digital transformations on entrepreneurial ecosystem in the eastern province of Saudi Arabia. Journal of Entrepreneurship Education, 23(1), 1-15.

Mariotto, F. L., Zanni, P. P., \& Moraes, G. H. S. (2014). What is the use of a single-case study in management research? Revista de Administração de Empresas, 54(4), 358-369.

Martinez Dy, A. (2019). Levelling the playing field? Towards a critical-social perspective on digital entrepreneurship. Futures, 102438. doi: 10.1016/j.futures.2019.102438.
Lessons from the fastest Brazilian unicorn 
Martins, J., \& Nunes, M. B. (2016). The temporal properties of e-learning: An exploratory study of academics' conceptions. International Journal of Educational Management, 30(1), 2-19.

McAdam, M. (2020). Digital girl: Cyberfeminism and the emancipatory potential of digital entrepreneurship in emerging economies. Small Business Economics, 349-362. doi: 10.1007/s11187-019-00301-2.

McAdam, M., Crowley, C., \& Harrison, R. T. (2018). Institutional voids and the emancipatory potential of digital entrepreneurship: Evidence from Saudi Arabia. In Paper Presented at the 78th Annual Meeting of the Academy of Management, AOM 2018.

McAdam, M., Crowley, C., \& Harrison, R. T. (2019). "To boldly go where no [man] has gone before" Institutional voids and the development of women's digital entrepreneurship. Technological Forecasting and Social Change, 146, 912-922. doi: 10.1016/j.techfore.2018.07.051.

Met, I., Uysal, E. U., Özkaya, K. S., \& Orç, E. (2020). Key success factors for strategic management in digital business. In Contributions to Management Science (pp. 283-304). Springer.

Mihardjo, L. W. W., Sasmoko, S., Alamsjah, F., \& Elidjen (2019). The influence of digital customer experience and electronic word of mouth on brand image and supply chain sustainable performance. Uncertain Supply Chain Management, 7(4), 691-702. doi: 10.5267/j.uscm.2019. 4.001 .

Ngoasong, M. Z. (2018). Digital entrepreneurship in a resource-scarce context: A focus on entrepreneurial digital competencies. Journal of Small Business and Enterprise Development, 25(3), 483-500. doi: 10.1108/JSBED-01-2017-0014.

Panda, B. K. (2019). Application of business model innovation for new enterprises: A case study of digital business using a freemium business model. Journal of Management Development, 39(4). doi: 10.1108/JMD-11-2018-0314.

Peter, M. K., Kraft, C., \& Lindeque, J. (2020). Strategic action fields of digital transformation: An exploration of the strategic action fields of Swiss SMEs and large enterprises. Journal of Strategy and Management, 13(1), 160-180. doi: 10.1108/JSMA-05-2019-0070.

Pin, C. (2014). Cluster policies and digital entrepreneurship in Ile-de-France (France) and in Lombardy (Italy). Innovations, 44(2), 79-104. doi: 10.3917/inno.044.0101.

Rantala, T., Ukko, J., Saunila, M., Puolakoski, H., \& Rantanen, H. (2019). Creating sustainable customer value through digitality. World Journal of Entrepreneurship, Management and Sustainable Development, 15(4), 325-340. doi: 10.1108/WJEMSD-08-2018-0077.

Ratzinger, D., Amess, K., Greenman, A., \& Mosey, S. (2018). The impact of digital start-up founders' higher education on reaching equity investment milestones. Journal of Technology Transfer, 43(3), 760-778. doi: 10.1007/s10961-017-9627-3.

Ravarini, A., Locoro, A., \& Martinez, M. (2020). Digital transformation projects maturity and managerial competences: A model and its preliminary assessment. In Paper Presented at the 15th Conference of the Italian chapter of Association for Information Systems, AIS 2018.

Remane, G., Hanelt, A., Nickerson, R. C., \& Kolbe, L. M. (2017). Discovering digital business models in traditional industries. Journal of Business Strategy, 38(2), 41-51. doi: 10.1108/JBS-10-2016-0127.

Ries, E. (2011). The lean startup: How today's entrepreneurs use continuous innovation to create radically successful businesses. Crown Publishing Group.

Rodrigues, C. D., \& de Noronha, M. E. S. (2021). What companies can learn from unicorn startups to overcome the COVID-19 crisis. Innovation and Management Review.

Sahut, J. M., Iandoli, L., \& Teulon, F. (2019). The age of digital entrepreneurship. Small Business Economics, 1159-1169. doi: 10.1007/s11187-019-00260-8.

Sanasi, S., Ghezzi, A., Cavallo, A., \& Rangone, A. (2019). Enacting business model change in digital startups: An exploratory multiple-case study. In Paper Presented at the 14th European Conference on Innovation and Entrepreneurship, ECIE 2019.

Slywotzky, A., \& Morrison, D. (2001). Becoming a digital business: It's not about technology. Strategy and Leadership, 29(2), 4-9. doi: 10.1108/10878570110387671. 
Sousa, M. J., \& Rocha, A. (2019). Skills for disruptive digital business. Journal of Business Research, 94, 257-263. doi: 10.1016/j.jbusres.2017.12.051.

Stoian, C. A., \& Tohanean, D. (2019). BMI in the digital era: Competitive advantage through human capital analytics. In Paper Presented at the 15th European Conference on Management, Leadership and Governance, ECMLG 2019.

Sturgeon, T. (2019). Upgrading strategies for the digital economy. Global Strategy Journal, 11(1), 34-57. doi: $10.1002 / g s j .1364$.

Sussan, F., \& Acs, Z. J. (2017). The digital entrepreneurial ecosystem. Small Business Economics, 49(1), 55-73. doi: 10.1007/s11187-017-9867-5.

Tangour, C., Gebauer, M., Fischer, L., \& Winkler, H. H. (2019). Digital business model patterns of big pharmaceutical companies - A cluster analysis. In 4th International Conference on Digital Economy, ICDEc 2019 (Vol. 358, pp. 397-412), Springer.

Tanrıkulu, F., \& Ermiş, M. (2021). Technology entrepreneurship and access to financial resources in Turkey. In Contributions to Management Science (pp. 107-120). Springer Science and Business Media Deutschland GmbH.

Thomas, L. D., \& Autio, E. (2020). Innovation Ecosystems in Management: An Organizing Typology. Oxford: Oxford University Press.

Tohanean, D., \& Weiss, P. (2019). Digital entrepreneurship and green business model innovation: Lean startup approaches. Quality - Access to Success, 20(S2), 630-634.

Tschanz, R., Cristo, S., Delgado, L., Hiroz, V., Jordan, M., Kalt, R., Mitchell, I., Müller, N., Roeoesli, C., \& Tamburello, V. (2020). "No innovation without cooperation" - How Switzerland innovation promotes cooperation between industry, research and startups. CHIMIA International Journal for Chemistry, 74(10), 755-757.

Ukko, J., Nasiri, M., Saunila, M., \& Rantala, T. (2019). Sustainability strategy as a moderator in the relationship between digital business strategy and financial performance. Journal of Cleaner Production, 236. doi: 10.1016/j.jclepro.2019.117626.

Vadana, I. I., Torkkeli, L., Kuivalainen, O., \& Saarenketo, S. (2020). Digitalization of companies in international entrepreneurship and marketing. International Marketing Review, 37(3), 471-492. doi: 10.1108/IMR-04-2018-0129.

Valdez-De-Leon, O. (2019). How to develop a digital ecosystem: A practical framework. Technology Innovation Management Review, 9(8), 43-54.

Wernerfelt, B. (1984). A resource-based view of the firm. Strategic Management Journal, 5(2), 171-180.

White, M. (2012). Digital workplaces: Vision and reality. Business Information Review, 29(4), 205-214. doi: $10.1177 / 0266382112470412$.

Whitley, E. A., \& Darking, M. (2006). Object lessons and invisible technologies. Journal of Information Technology, 21(3), 176-184. doi: 10.1057/palgrave.jit.2000065.

Wiesböck, F., \& Hess, T. (2020). Digital innovations: Embedding in organizations. Electronic Markets, 30(1), 75-86. doi: 10.1007/s12525-019-00364-9.

Yin, R. (2003). Case study research: Design and methods (Vol. 761). Thousand Oaks: Sage Publications.

Zahra, S. A. (2021). The resource-based view, resourcefulness, and resource management in startup firms: A proposed research agenda. Journal of Management. doi: 10.1177/01492063211018505.

\section{Corresponding author}

André Luiz Tavares Damasceno can be contacted at: altdamasceno@gmail.com Associate Editor: Felipe Borini

For instructions on how to order reprints of this article, please visit our website:

www.emeraldgrouppublishing.com/licensing/reprints.htm

Or contact us for further details: permissions@emeraldinsight.com
Lessons from the fastest Brazilian unicorn 